\title{
Assessing Transit Station Area Redevelopment: A Case Study of the Lindbergh Station in Atlanta
}

\author{
Lawrence D. Frank, Georgia Institute of Technology \\ Mollie Stephenson Smith, CRA Associated, Inc. \\ Eleanor Q. Matthews, MARKETEK, Inc.
}

\begin{abstract}
$\overline{\text { Abstract }}$
This article assesses the land-use, demographic, circulation, and economic development attributes of transit station area development. Findings from this assessment are applied to the Lindbergh Metropolitan Atlanta Rapid Transit Authority (MARTA) Station area in Atlanta, Georgia, for which a private-public partnership is currently being negotiated. Recommendations for the redevelopment of the Lindbergh Station area are provided, including a schematic design that integrates those recommendations. The resulting recommendations are intended to maximize the likelihood for transit ridership and economic benefit while offsetting traffic congestion and vehicle emissions-in keeping with the objectives of the Federal Transit Administration's Livable Communities Initiative. A safe and inviting walking environment throughout a station area-extending well beyond the area of physical redevelopment itself-is fundamental to achieving these objectives. Existing barrier effects and lack of pedestrian
\end{abstract}


connectivity associated with major transportation corridors within the Lindbergh Station area will significantly offset transportation and environmental benefits on which public investment in the redevelopment is predicated. Solutions are required that provide not only safer street crossings, but a larger proportion of rights-of-way devoted to pedestrian movement and the development of a "street life." Priority should be given to pedestrian improvements that increase access to transit for traditionally underserved populations. Finally, open space is required to effectively compete with other more auto-dependent areas and to draw higher income populations to transit station areas.

\section{Introduction}

Many growing metropolitan areas throughout the nation are faced with increasing levels of traffic congestion, sprawling development, socially isolated communities, and poor air quality. Development patterns and transportation investments collectively shape not only the arrangement of activities in the urban landscape, but also determine the relative ease of travel by mode. An obvious alternative to auto-dependent "green-field" development is the reinvestment within existing centers. This article explores the potential for reinvestment around transit stations, in particular where walking and transit should be viable options to the automobile. Assessing the likely implications of alternative approaches to redeveloping transit station areas can be supported through a holistic approach at addressing the creation of a set of criteria or performance measures that address circulation, land- use, demographic, and economic development concerns. Past research also suggests that significant coordination is required among federal, state, regional, and local agencies to implement strategies aimed at confronting urban problems that extend to a regional scale. Institutional mechanisms are required to prioritize nonmotorized circulation within station areas. This requires an investment program that extends well beyond those parcels that are under redevelopment.

The Atlanta region is currently without a long-range transportation plan that conforms with national air quality requirements specified in the Clean Air Act and detailed in the National Ambient Air Quality Standards. This means that the region is currently without an adopted strategy capable of achieving 
compliance with federal air quality mandates. Underpinning the inability to develop a conforming transportation plan is the allocation of growth, in terms of the specified location of future households and jobs, that has been modeled by the Atlanta Regional Commission. As currently modeled, the vast majority of growth would go to the urban fringe-and the modeling results suggest that this, among other factors, leads to ever increasing auto dependence and bad air. One alternative to this scenario is to focus a portion of the growth into locations where alternatives to the single-occupant vehicle (SOV) exist.' This article explores the redevelopment of an existing transit station area as a case study to evaluate the potential for improving regional air quality and transportation conditions by capitalizing on existing transit investments.

\section{Transit Supportive Development}

An extensive literature defining transit-oriented development (TOD) currently exists. This article applies the empirical research embedded in this literature through the development of a system of land-use, demographic, circulation, and economic development attributes that interactively define a program for redevelopment. The conceptual model for this system is depicted in Figure 1.

The figure illustrates specific attributes that need to be addressed within an effective redevelopment plan. It is critical to have a program for redevelopment that defines the appropriate combination of land-use and demographic mix and supportive circulation improvements, confirmed against a carefully researched economic development program. Transit-supportive development refers to an urban environment characterized by moderate- to high-density residential, and a mix of commercial and retail uses, all in close proximity to the local or regional transit system. In addition to simply accommodating projected growth, the goals of TOD are to increase transit ridership, improve the quality of life in urban areas, and enhance economic vitality. Related objectives include:

1. using infill and redevelopment to maximize the use of existing urbanized areas already accessible to transit;

2. employing land-use strategies to reinforce transit use; 


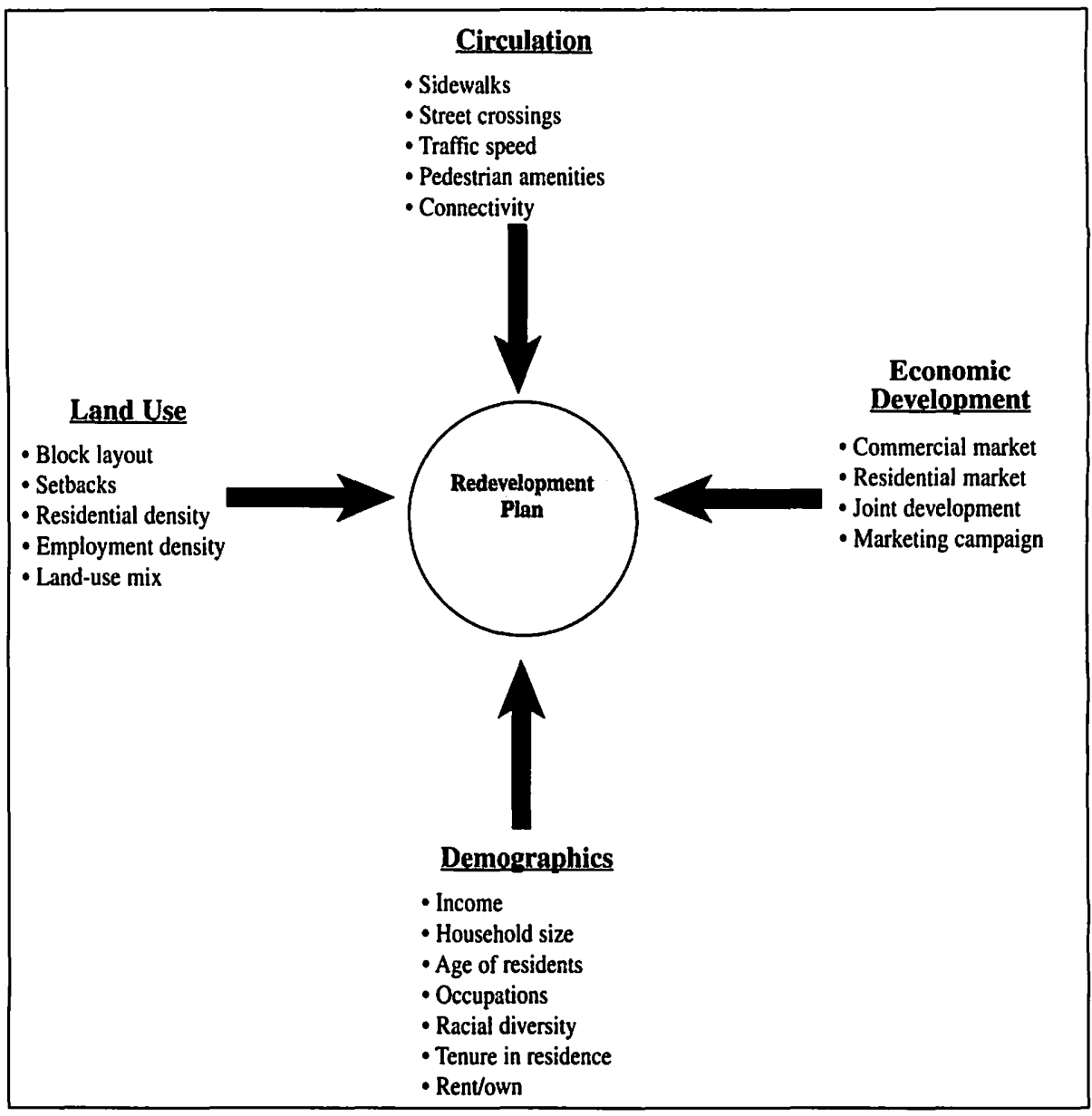

\section{Figure 1. Attributes of transit-oriented development}

3. creating an environment that presents numerous opportunities to walk and bike, thereby reducing the number of automobile trips and vehicle miles traveled in the immediate area and larger region; and

4. fostering a 24-hour community that is more vital, interactive, and secure than many of today's typical neighborhoods.

These benefits, however, are contingent on successful implementation. For example, transit-supportive development requires coordination between agencies and all levels of government, along with partnerships between and among developers, neighborhoods, transit authorities, and local government. 
Success of these relationships also requires understanding of available funding sources. ${ }^{2}$

\section{Land-Use Considerations}

The literature on TOD establishes several key conceptual components. Many researchers have focused on the importance of land use, particularly on the effect of intermixing uses, the compactness of development, and street connectivity. The geographic scale at which uses are intermixed impacts the distances that need to be traversed to reach a complementary use (e.g., a store from home or work). The compactness of development, most often measured as the density or numbers of households and jobs per unit of area, captures a multitude of demographic and urban form factors associated with travel choice. The degree to which the street network is interconnected, ranging between a gridiron plan (most connected) to a cul-de-sac form (disconnected) determines the level of ease that destinations can be reached. These land-use measures interact. A measure of land-se mix may indicate that a neighborhood has a wide variety of uses all within short crow-fly walking distances-but few people are walking due to the lack of direct pedestrian linkages between these different land uses (Frank 1998).

The question of what uses should be included, and in what proportion, is more complex. Calthorpe (1993) defines the ideal land-use mix for neighborhood TODs as 10 percent to 15 percent public use, 10 percent to 40 percent core/employment, and 50 percent to 80 percent housing. Others stress the importance of retail uses, claiming they can yield almost as many transportation benefits in residential neighborhoods as can higher densities (Bernick and Cervero 1997), a second important factor in encouraging transit and pedestrian activity.

Numerous studies document that density is a critical component of a set of factors that are required to facilitate transit ridership. In Urban Rail in America, Pushkarev, Zupan, and Camella (1982) note the importance of transit-supportive development patterns at both trip origins and destinations. More specifically, they note the need for a minimum level of residential density at the production end and a critical mass of development at the destination or employment trip end for transit to be efficient and competitive. In an exami- 
nation of six metropolitan areas, ranging from Springfield, Massachusetts, to New York City, transit ridership rose marginally when residential densities were increased from 7 dwelling units per acre to 16 (Bernick and Cervero 1997). Density of workplaces has also been found to lead to increased transit use. A study of Bellevue, Washington, a city having a mean workplace floor area ratio of 7.4 , found that 27 percent of its employees reached the office by bus, carpool, or vanpool (Cervero and Gorham 1995). This is a relatively high modal share for transit for a modern suburban center of moderate development densities. The higher level of transit usage can be explained by regional congestion, aggressive transportation demand management efforts pursuant to Commute Trip Reduction efforts, and a high-quality transit service that includes regional express service often operating on less clogged high-occupant vehicle facilities. Another study of the Seattle metropolitan region found that auto use decreased and transit and walk trips increased when employment densities of more than 75 workers per acre were reached (Frank and Pivo 1994). These shifts in travel from the personal vehicle to transit and walking associated here with higher levels of employment density reflect other market forces that occur with higher concentrations of development-namely the increased cost and the reduced availability of parking.

Other important land-use factors focus on design issues such as block size, connectivity, and building setbacks. Downtown Portland, Oregon, is an often-cited example of how a uniformly small block size has helped to create a pedestrian- and transit-supportive environment (City of Portland 1980). A street pattern that uses an interconnected grid, where adjacent developments are linked together, allows for a number of alternative routes for both pedestrian and vehicular traffic. This adds variety for pedestrians, who, as a result, have more paths to travel between activities (Calthorpe 1993). It also allows local trips between the home and nearby attractions to be made without using the major arterial street network (Metro 1997). This is a very important safety consideration for families with younger children.

Calthorpe (1993) also observes that minimal setbacks encourage pedestrian activity by bringing buildings close to the street. Buildings should be as close 
to the street as possible, although setbacks of up to 20 feet can be allowed for larger office buildings in commercial areas. The closeness of the buildings to the street also serves to narrow the street and helps to slow traffic; the planting of trees in planting strips (if there is enough room) or on the median of a street can have the same effect. In residential areas the setback should be 10 feet to 15 feet, allowing some privacy while keeping the buildings close to the street.

\section{Demographic Considerations}

A variety of studies illustrate that land use and the level of transit service are not the sole factors that impact travel choice; and, in some instances, are regarded as having a relatively inconsequential influence when compared with household demographics. Household demographic characteristics that explain travel behavior include income, life cycle stage, automobile availability, household size, and ownership (Ewing, Haliyur, and Page 1994; Cervero and Kockelman 1997). Most people that inhabit successful TODs are between 25 and 34 years old, and 65 years old and over. While median household income tends to be relatively low compared with many suburban communities, there is an increasing demand for high-quality housing located within close proximity to transit. Childless households and in-migrants from foreign countries are other important demographic candidates for transit-oriented living (Cervero and Kockelman 1997). These households tend to be small, occupy less space, and are more inclined toward multifamily settings.

Clearly, the ideal population of a transit-oriented community can best be characterized by its diversity. However, in areas where retrofit is taking place, efforts to preserve the area's diversity are essential. This is a very important consideration within the Lindbergh Station area in Atlanta, which has concentrations of white, black, Hispanic, and Asian populations within close proximity. ${ }^{3}$ The level of automobile ownership is also a reliable indicator of a household's degree of attraction to transit-supportive development. Most rail-served apartments and condominiums are small in size with relatively low vehicle ownership (Bernick and Cervero 1997). Conversely, several studies have further documented that increasing levels of auto ownership are associated with reduced transit ridership (Frank 1999; Schimek 1996). Finally, it has been 
found that the population of transit-based housing should have large concentrations of managerial and professional workers. Only a few residents of transit-based housing work in sales, service, and other occupations (Bernick and Cervero 1997).

\section{Circulation Patterns}

While the importance of land use cannot be overstated, characteristics of the transportation network itself play an enormous role in a successful TOD. A fundamental criterion of TOD is the ease and degree of attractiveness for local travel on foot. Utilitarian factors, such as the ease of street crossings, sidewalk continuity, signal placement, local street characteristics, and topography (Parsons, Brinckerhoff, Quade, and Douglas Inc. 1993; Florida Department of Transportation 1995) must be considered during planning stages of the TOD. Other important elements are aesthetic in nature, including the presence of lighting, landscaping, and street furniture. People are attracted to places that are quiet, well maintained, and conducive to relaxation and social contact (Untermann 1984). Antoniou (1971) provides a very thorough description of factors that must be considered when planning for the pedestrian, including facilities and amenities, maintenance, and the provision of public utilities to the area under consideration. Sidewalk widths should be large enough to easily accommodate the expected pedestrian flow; lighting should be sufficient for both safety and attractiveness; and amenities should be chosen and placed based on expected flow and usage.

Moudon et al. (1996) theorized that the low incidence of pedestrian travel in mixed-use, medium-density environments located in many suburban settings is due to inadequate site design. Even in areas spatially conducive to walking, a lack of direct, continuous, and safe pedestrian systems will prevent people from choosing to walk. This condition is termed "low connectivity." Though empirical evidence relating pedestrian behavior to site design in medium-density settings is scarce, it does suggest that pedestrian travel is a viable alternative to the SOV for a portion of the population under specific circumstances. Isolating those circumstances and then ensuring their provision is therefore key to providing for a successful pedestrian environment. 
An obvious component of the circulation network is the flow of vehicular traffic on the roadway system. One way that traffic flow can be structured to allow for pedestrian access while maintaining vehicle capacity involves the formation of directional couplets resulting in a narrower vehicular right-ofway between pedestrian refuges. ${ }^{4}$ Other practices that often result in the reduction of traffic volume and speed include the elimination or rerouting of through traffic, provision of midblock crossings, and development of internal pedestrian shopping areas (Untermann 1984). One measure of the degree of pedestrian friendliness is the proportion of the right-of-way devoted to pedestrian movement. The Florida Department of Transportation (1995) suggests an ideal overall ratio of 50:50 of pedestrian space to vehicle space on targeted corridors within TODs.

Many other considerations are necessary when planning pedestrian facilities in areas of substantial automobile traffic. Intersections are one of the most obvious areas of concern and should be clearly designed for ease of pedestrian crossing and maneuverability. Geometry of the roadway should be designed in order to slow traffic and allow pedestrians to safely share the facility; signal placement should be easily seen by the pedestrian; and sidewalks and crosswalks at or near intersections should be well lit. Raised medians should be provided so that pedestrians are given opportunity for refuge midway through the street crossing (Florida Department of Transportation 1995).

\section{Economic Development}

Economic development has not been as well researched as other aspects of TOD. Newman and Kenworthy (1996) point out that transit investment can have twice the economic benefit to a city as highway investment. Transit focuses access in a manner that enables higher densities, which in turn creates more efficient subcenters, which can offset sprawl. In addition, transit enables a region to become more corridor oriented, making the provision of infrastructure easier and less expensive (Burchell and Listoken 1974). The economic development point of view should be carefully considered when assessing an area's potential for successful TOD. However, it should be addressed within the larger context of the other issues outlined here as well. Berechman (1995) 
states that in evaluating the economic development potential of a transit station area, it is necessary to consider the travel and socioeconomic characteristics of the area, the transport attributes of the project, and its relationship to the wider transport network.

The ability of a project to maximize its potential requires a careful assessment of the residential and commercial land markets within a defined competitive trade area. Residential location is a complex decision process underpinned by a set of attributes. The ability to maximize the attractiveness of a station area as a residential location requires knowing the market. For example, the ability to attract high-end clientele will require understanding of the amount and character of open space that is perceived as a competitive amenity to having one's own yard. For low-income residents, the proximity to transit may help a great deal, but given the high rate of vehicle ownership, even among low-income households, a competitive rental price will often remain an overriding factor.

An integrated approach to assessing the transportation, land-use, and economic development attributes of station area development is not typically undertaken during the assessment and planning phases of TOD. Economic development interests are indeed the most common foundation of land development and transportation actions. However, a careful assessment of the underlying market forces driving the demand for an assumed real estate product is often omitted from the transportation planning process. The following case study of the Lindbergh Station area redevelopment suggests that transit operators, developers, and environmentalists may find themselves with very closely allied objectives. Where travel by transit or on foot is highly sensitive to a certain level of density or compactness, the same holds true for the developer whose profit is contingent upon the number of sellable units that are created within a project.

\section{The Lindbergh Station Area}

This case study began as an assessment of redevelopment plans for the area surrounding Lindbergh Station, an intown stop on the MARTA rail system 
(Figure 2). The goal of the study was to create a set of measures and design tools that could be used to guide the final redevelopment program. Recommendations were developed in partnership with the City of Atlanta's Planning Bureau and MARTA.

The project expanded on the Transit Station Area Development (TSAD) Study for the Lindbergh Station area, which was completed by a team of consultants in January 1998. The City of Atlanta wanted to supplement the TSAD effort with more in-depth information on the travel behavior, air quality, pedestrian accessibility, and economic development potentials of various approaches to redevelopment. Additional research was conducted, literature reviews of relevant case studies were performed, and transit-supportive development recommendations were specified for the area. These will be used by the City in

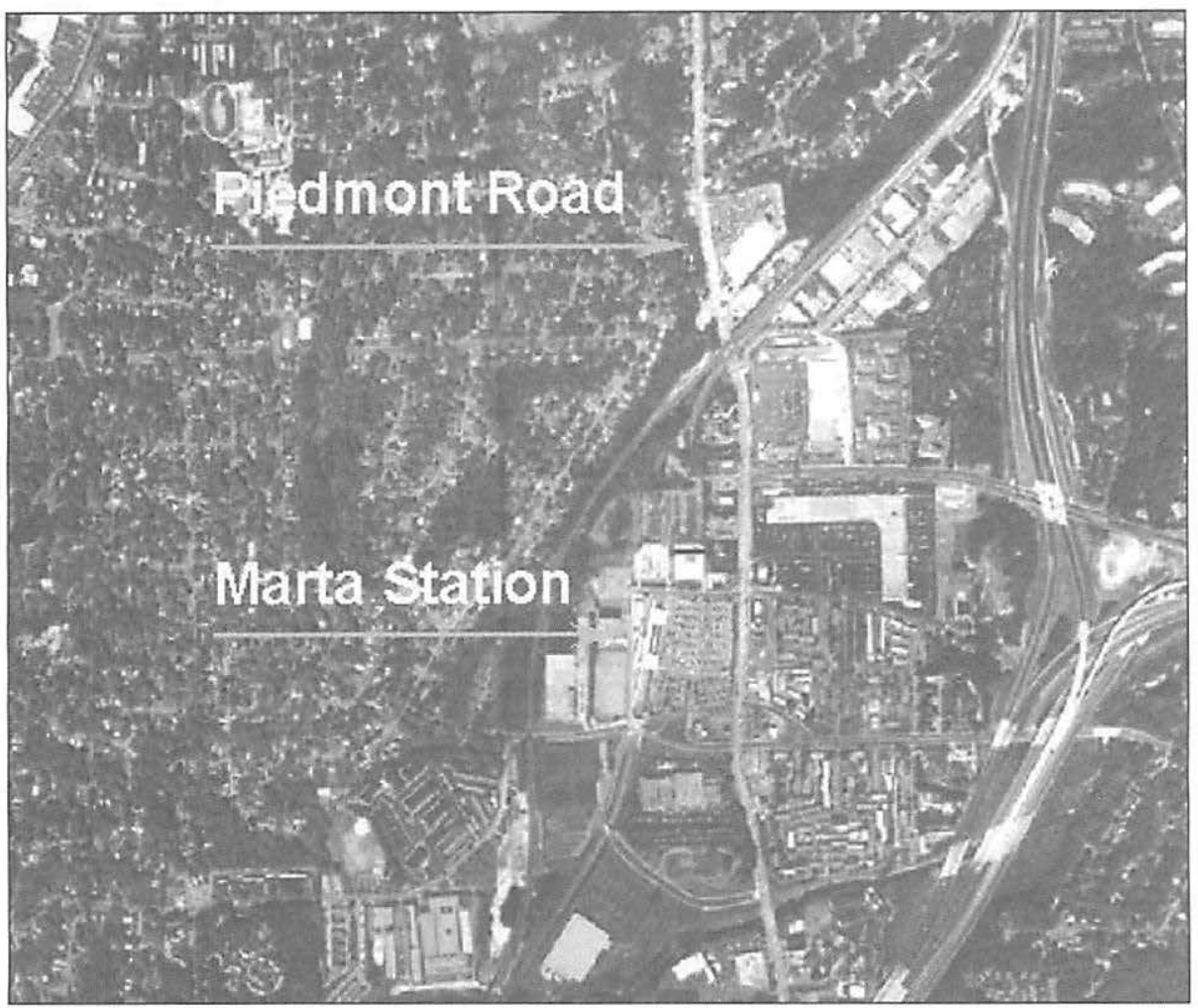

Figure 2. Existing land-use and circulation conditions at Lindbergh Station 
evaluating the environmental and transportation benefits associated with current and future redevelopment proposals. The information gathered has been used by local neighborhoods in their efforts to minimize the negative traffic impacts associated with more concentrated development.

The three goals for the redevelopment of the Lindbergh Station area, as stated by MARTA and the City of Atlanta, are to: (1) increase transit ridership (2) foster economic development, and (3) establish a sense of community. These three goals are roughly aligned with those of the Federal Transit Administration's (FTA) Livable Communities Initiative. ${ }^{5}$ Establishing a "livable community" that offers alternatives to auto-dependent land-use patterns found elsewhere in the Atlanta region also offers an important promise for the reduction of vehicle emissions. Given the air quality problems faced within the Atlanta region, a fourth goal was added for the redevelopment effort: implement a model development pattern that supports multimodal accessibility, reduced auto dependence, and decreased air pollution.

These goals were addressed in the project through four specific task areas, defined in Figure 1: land use, demographics, transportation, and economic development.

\section{Station Area Analysis}

An analysis of existing land-use and demographic conditions was performed using census data, employment security data, and assessors' parcellevel data at the block and block-group levels. Factors included in the analysis were age, income, employment, ethnicity, tenure in residence, housing value, and other household characteristics. Current levels of land-use intensity (both employment and residential density), mix, and connectivity were also assessed.

Land Use. An examination of land-use conditions showed that the Lindbergh study area contains 91 blocks and 576 hectares (approximately 1,422 acres). The average block is more than 15 acres in size - far higher than what might be considered a more walkable scale at between 2 and 5 acres (City of Portland 1980). The western portion of the study area is predominantly singlefamily residential, while other portions include more multifamily apartment buildings. Within the last year, formerly vacant land near MARTA's north-south 
line has been developed into an upscale multifamily apartment complex of 396 residential units. ${ }^{6}$ Much of the land in the study area is owned by MARTA and is used for the Lindbergh MARTA Station, the MARTA headquarters building, and parking. The remaining land in the study area is used for various forms of commercial development. Figure 2 conveys the layout of existing development in the station area including single-family residential to the east and high-density commercial develop along the Piedmont Road corridor.

Demographics. Racial distribution and placement within the study area were examined. White residents make up 72.4 percent of the Lindbergh study area and are evenly distributed throughout. Most of the remainder is either Hispanic (10.1\%) or black (10.9\%), and 3.7 percent are Asian. Nearly all of the minority concentrations are located in the eastern portion of the study areato the east of Piedmont Road. Overall, the population in the study area is fairly well educated, with 33 percent having earned a bachelor's degree, 20 percent having some college but no degree, and 17 percent having a graduate or professional degree. The largest percent of occupants in the study area works in the managerial/professional sector, comprising about 44 percent of the study area's workforce. Many residents (29\%) also work in sales/services. Most block groups east of the MARTA station have a median income of less than $\$ 20,000$. Block groups south of the MARTA station have median incomes between $\$ 20,000$ and $\$ 40,000$. The more affluent residents tend to live to the north and west of the MARTA station and have median incomes ranging from $\$ 40,000$ to $\$ 60,000$ - consistent with the racial distribution noted above. The mean number of vehicles per household in the Lindbergh area is 2.79 . Thirtyseven percent of the residences in the study area are owner-occupied.' A majority of these were detached, single-family houses. The remaining 63 percent of the housing supply, in the form of rental units, are low-rise, two-story units, located along Piedmont and Lindbergh Roads and at the eastern boundary of the study area. There is no significant supply of attached, owner-occupied housing in the study area at present. The median house value is in the range of $\$ 175,000$ to $\$ 199,000$. $^{8}$ Approximately 70 percent of the housing values are more than $\$ 150,000$. 


\section{Transportation}

The initial assessment of circulation conditions examined vehicular access, pedestrian access, transit access, and safety. Deficiencies in the existing pedestrian network were cataloged, including sidewalk disconnects, driveways, and facilities for the disabled. Parking data obtained from MARTA were supplemented by conducting a three-day parking study to assess the utilization of surface lots in the study area. Within the Lindbergh Center area, as in most of the Atlanta region, the predominant mode of travel is the automobile. Piedmont Road, a six-lane state route, divides the study area into eastern and western portions and allows a heavy volume of traffic to traverse the study area at high speeds. The fact that most of the traffic is "cut through" is indicated by the peak traffic times, which are 8 A.M. and 5:15 P.M. Lack of on-street parking, the visual effect of existing land uses, scale of signage, and signal timing all play an additional part in the high speeds observed on Piedmont Road. The posted speed limit on Piedmont Road is 40 miles per hour. While no formal speed studies were undertaken, simply driving through the area made it apparent that average speeds are much higher than the speed limit. This is not too surprising given that every step is taken to maximize vehicle traffic flow and the high-design speed along this thoroughfare.

An origin-destination study of the Lindbergh MARTA Station park-andride patrons confirms a high proportion of drive-alones and those using MARTA to avoid the inbound traffic on the downtown freeway. Most of these trips terminate at locations outside the study area-mainly downtown-suggesting that the study area is basically a transfer point instead of a destination.' Surface parking comprises 65 acres, corresponding with a significant proportion of the study area (Figure 2). The monthly utilization of the MARTA surface lot, which is free of charge, averages 77 percent. The MARTA employee deck, for which a parking fee is charged (\$3), averages a 75 percent utilization rate. The parking utilization for the area's two shopping centers, located to the east of Piedmont, is not as high. Estimates performed over a three-day period indicated that these lots are heavily underutilized, especially during the weekday, when utilization rates ranging between 25 percent and 50 percent were 
observed. Collectively, the lots have a 35 percent utilization rate based on the three-day average. Conditions for pedestrians within the Lindbergh Station area are hazardous and unpleasant. The intersection of Piedmont and Lindbergh Roads has been the scene of numerous pedestrian-vehicle conflicts. Figure 3 conveys the characteristics of the pedestrian environment of the Lindbergh Station area, and Table 1 details the incidents involving pedestrians that took place in the area in 1995.

Piedmont Road, the area's main roadway, has a daily traffic volume of more than 42,000 vehicles. Five motor vehicle incidents involving pedestrians took place in the study area during 1995. All but one of those occurred on Piedmont Road. During site visits, the area's pedestrian network was mapped, focusing primarily on pedestrians and Americans with Disabilities Act (ADA) disconnects. In addition to sidewalks that abruptly stop, many areas do not have the curb cuts or sidewalk width mandated by the ADA of 1990 . Of greatest concern is the fact that several intersections have handicapped ramps on one corner but not on the other, essentially trapping the wheelchair-bound person who ventures into the intersection without surveying the far side. Another pedestrian issue is the difficulty involved in safely crossing Piedmont Road. Currently, inadequate crosswalks and signal timing make it a hazardous traverse. The width of the crosswalks does not adequately accommodate peak pedestrian flows. The narrow, mountable medians on Piedmont Road are also inadequate and terminate a significant distance before each intersection. The protection provided by the medians is also limited by their low height, as motorists can easily drive up and over these curbs.

Transportation recommendations resulting from this analysis focused on pedestrian facilities-especially sidewalks and crosswalks.

- "Collector" sidewalks should not be less than 3 meters in width; all other sidewalks should not be less than 2 meters in width.

- Pedestrians should be able to cross all local streets at every logical crossing point, and each intersection should have a clearly defined crosswalk with (1) pavement striping and (2) pedestrian buttons and signal displays. 


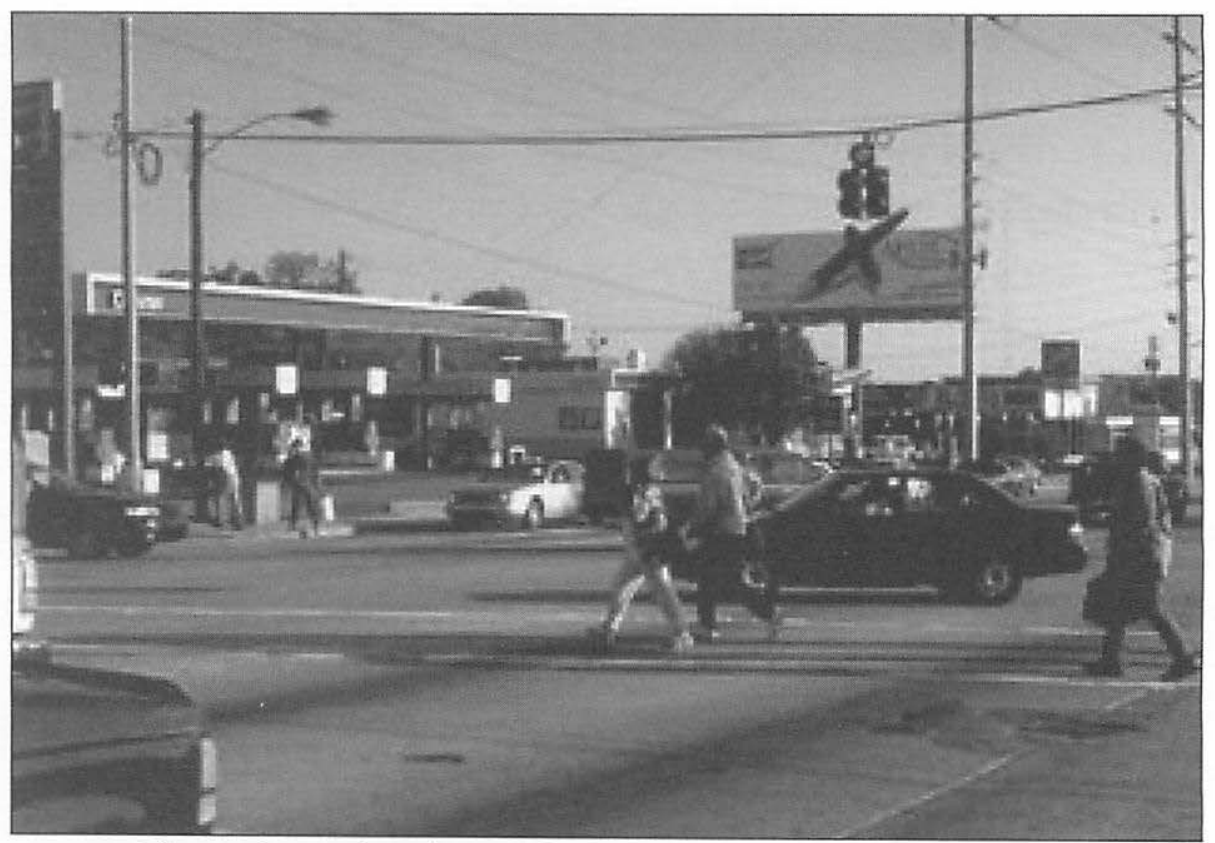

Figure 3. "Pedestrian environment" along Piedmont Road

\begin{tabular}{|c|l|l|l|l|l|l|}
\hline \multicolumn{2}{|c|}{ Intersection } & & $\begin{array}{l}\text { Vehicle } \\
\text { Maneuver }\end{array}$ & $\begin{array}{l}\text { Pedestrian } \\
\text { Maneuver }\end{array}$ & $\begin{array}{l}\text { Contributing } \\
\text { Factor }\end{array}$ & $\begin{array}{l}\text { Traffic } \\
\text { Control }\end{array}$ \\
\hline 1 & Piedmont Road & Morosgo Drive & Straight & $\begin{array}{l}\text { Crossing at } \\
\text { crosswalk }\end{array}$ & $\begin{array}{l}\text { Disregard stop } \\
\text { sign/signal }\end{array}$ & $\begin{array}{l}\text { Traffic } \\
\text { signal }\end{array}$ \\
\hline 2 & Lindbergh Drive & Adina Drive & - & $\begin{array}{l}\text { Crossing, } \\
\text { not at } \\
\text { crosswalk }\end{array}$ & - & - \\
\hline 3 & Piedmont Road & $\begin{array}{l}\text { Sydney Marcus } \\
\text { Boulevard }\end{array}$ & $\begin{array}{l}\text { Turning } \\
\text { left }\end{array}$ & $\begin{array}{l}\text { Crossing, } \\
\text { not at } \\
\text { crosswalk }\end{array}$ & Failed to & $\begin{array}{l}\text { Traffic } \\
\text { signal }\end{array}$ \\
\hline 4 & Piedmont Road & Miami Circle & $\begin{array}{l}\text { Turning } \\
\text { right }\end{array}$ & $\begin{array}{l}\text { Crossing, } \\
\text { not at } \\
\text { crosswalk }\end{array}$ & - & $\begin{array}{l}\text { Stop or } \\
\text { yield } \\
\text { sign }\end{array}$ \\
\hline 5 & Piedmont Road & Miami Circle & $\begin{array}{l}\text { Entering/ } \\
\text { leaving } \\
\text { driveway }\end{array}$ & $\begin{array}{l}\text { Crossing at } \\
\text { crosswalk }\end{array}$ & - & Lanes \\
\hline
\end{tabular}

Table 1. 1995 Pedestrian Incidents 
- Wheelchair ramps should be provided at each side of each intersection as well as at both sides of all medians. Pedestrian buttons should be well within the reach of a person in a wheelchair.

- Signal phasing should provide one second of protected crossing time per each meter of street width.

- Roadways of four or more lanes should have raised medians that extend to the edge of denoted crosswalks.

- Where sidewalks run directly parallel to roadways, a buffer should be provided to shield the pedestrians from the sights and sounds of traffic and to diminish the opportunity for pedestrian-vehicle incidents to occur. Vehicles parked on the street can serve as a buffer between moving traffic and sidewalks and this is noted as a logical solution within the literature.

The circulation recommendations for the Lindbergh Station area include specific steps necessary to improve the pedestrian orientation of the area. However, additional changes to the transportation system are required to accommodate these solutions while still maintaining adequate vehicular flow levels. Three primary design components to be executed in the first phase of the overall redevelopment scheme were identified and are shown in Figure 4 (north is up).

These changes to the transportation system include an extension of Sidney Marcus Boulevard, one of the area's primary roadways, which extends from Piedmont Road to Lindbergh Drive. This will result in the formation of a parallel north-south corridor to the west of Piedmont Road in the study area. This plan includes the conversion of Piedmont Road between Lindbergh Drive and Sidney Marcus Boulevard to a one-way boulevard for northbound traffic. ${ }^{10}$ As a result, the overall vehicle-moving capacity of the Piedmont Road corridor is maintained through the study area while effectively reducing the crossing distance for pedestrians for each direction of travel. Finally, Morosgo Drive, a secondary north-south street to the east of Piedmont Road, should be restricted to transit buses and service vehicles. 


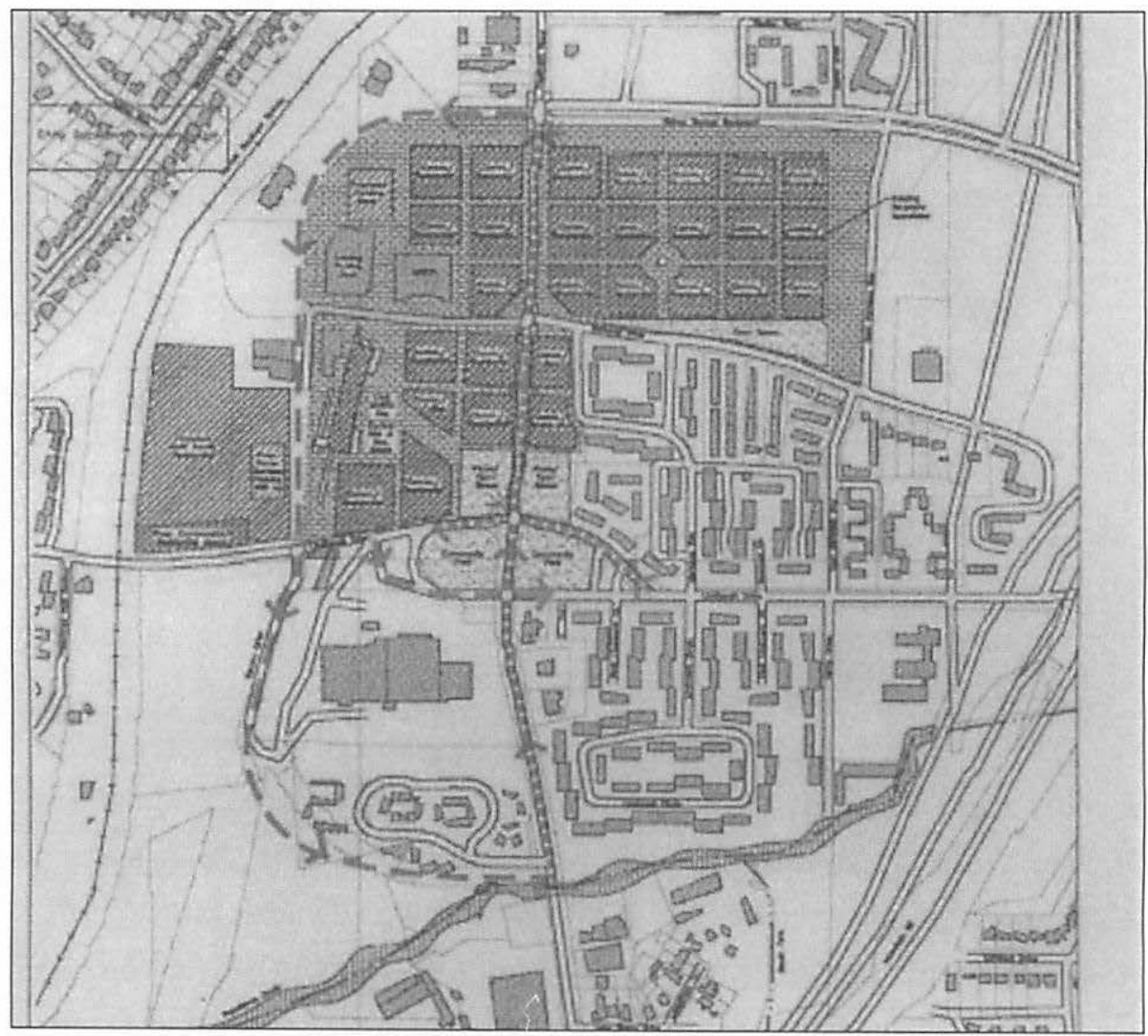

Figure 4. Proposed schematic design

These recommendations were designed to relieve congestion and improve pedestrian safety within the station area. The recommendation also stipulated special treatment of intersections, including the use of bulb-outs at the end of the parking lanes and brick or colored pavers to communicate the unique identity of the Lindbergh Station area and alert drivers that they are entering a heavily pedestrian-oriented zone. The final transportation-related recommendation was to remedy the numerous pedestrian disconnects within the station area. ${ }^{\prime \prime}$ These strategies will improve the pedestrian orientation of the area while maintaining adequate vehicular flow levels.

\section{Economic Development}

Land-use and transportation issues are, to some degree, necessary components of the TOD planning process. These issues are usually considered 
when planning such projects, although the depth of analysis varies. Economic development, however, is not always an element of TOD planning and design processes, an omission that can risk the marketability and economic viability of the final project. The concepts of physical and demographic market identification have been incorporated into this assessment of the Lindbergh Station area, resulting in a final analysis that is more thorough and practical than if undertaken with only a physical-planning orientation. An examination was made of the current conditions and potential demand in the Lindbergh/Piedmont market areas--both residential and commercial—and recommendations were made for meeting this demand.

Estimating Residential Demand. First, a primary market area was delineated to serve as the geographic base for the evaluation of potential market support for rental and for-sale residential uses at the Lindbergh Station site. The primary market area is generally defined as that geographic area from which the majority of buyers or renters will be drawn. Figure 5 shows the primary market area that was defined for residential product, bounded on the north by I-285; on the south by the Georgia Railroad; on the east by I-285; and on the west by the Chattahoochee River, Marietta Boulevard, and the Southern Railroad.

Next, a demographic profile for the primary market area was created using the Demographic and Income Forecast provided by CACI Marketing Systems, Inc., including population and household growth trends, age and household income distributions, and race and ethnicity trends. Data for the primary market area were compared with the same data for the Atlanta metropolitan area. A potential demand analysis was performed for the primary market area to estimate the market depth for rental apartments targeted at households with annual incomes from $\$ 25,000$ to $\$ 50,000$. The income categories used for potential homeowners are those in excess of $\$ 35,000$ and assume monthly housing costs for both renter- and owner-occupied units that average 30 percent of monthly gross household income.

The two main sources of demand for housing within the primary market area are new household growth and renter or owner turnover. New household growth is traditionally used to project market growth and is based on popula- 


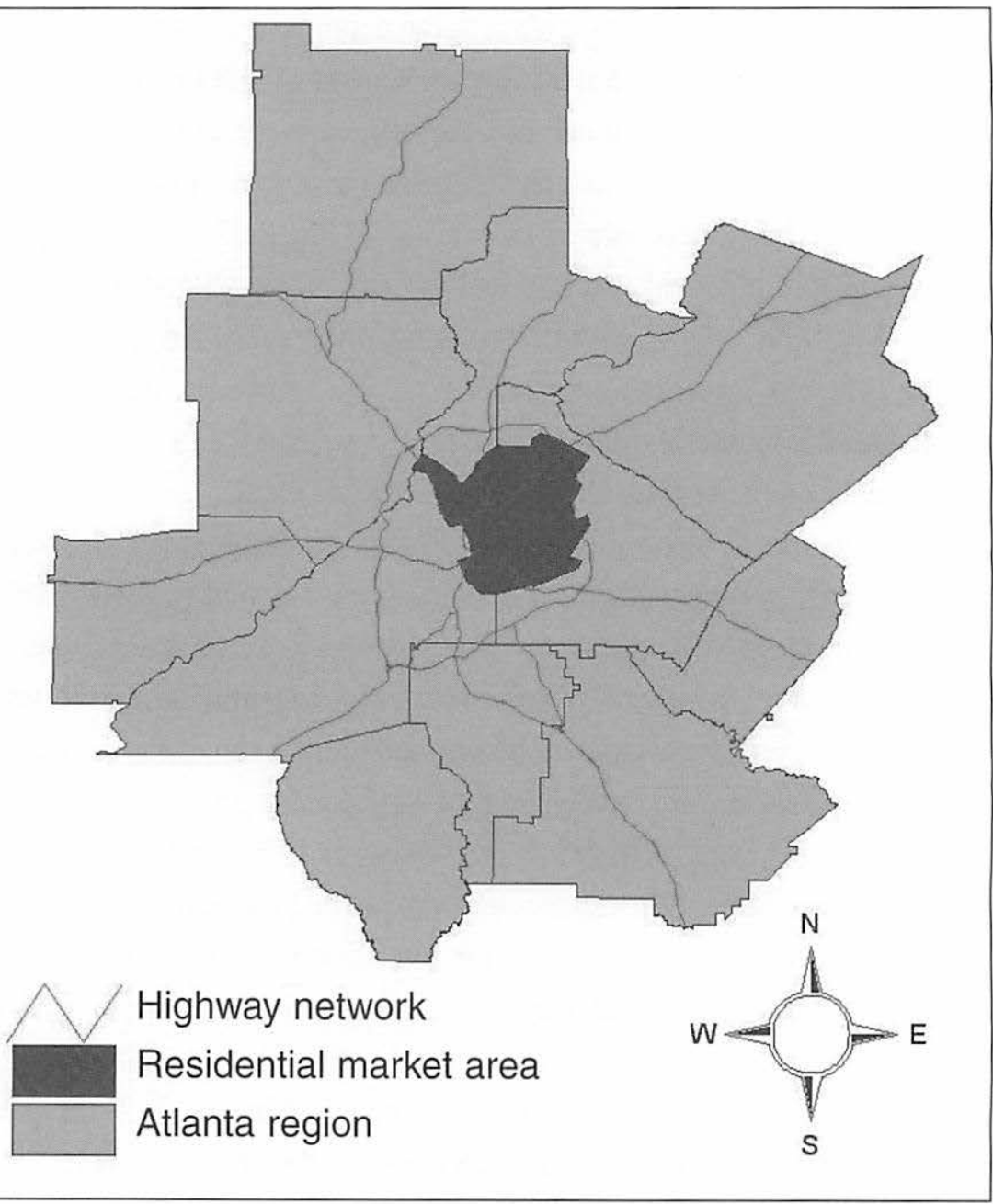

Figure 5. Residential market area

tion and household growth projections. Estimates of occupied housing units by tenure provide the base for estimating the number of households that will be renters or owners. Renter or owner turnover is a more quantitatively significant source of demand and is based on the estimated number of renter or owneroccupied units that will exist within the market area during the next five years.

The data sources for the potential demand analysis included population estimates and projections and age and income distributions provided by $\mathrm{CACI}$ 
Marketing Systems, Inc., and housing characteristics contained in the 1990 census. Even though the potential demand analysis used finite numbers, its end result (i.e., potential market support) was interpreted as an approximation of market depth that was balanced with the results of an analysis of the competitive supply. The supply analysis was used to support both quantitative and qualitative aspects of the recommended product program.

The geographic base for the analysis of the housing supply was the competitive market area, defined as the geographic area within which similar projects compete with one another on an approximately equal basis (Figure 5). The competitive residential market area used for this project is bounded on the north by Dresden Drive, on the south by Ponce de Leon Avenue, on the east by Clairmont Road, and on the west by Piedmont Road. Within the competitive market area, seven submarkets were identified based on the types and quality of housing prevailing in each. These submarkets were surveyed to obtain age of project, unit types, unit mix, rental rates/sales prices, value ratios (dollars per square foot), occupancy rates, absorption histories, amenities, and renter/owner profiles.

The final result of the potential demand analysis for renter and owneroccupied housing provided an estimate of annual market support for new housing in the primary market area. A recommended residential development program for both rental and for-sale product at the Lindbergh Station site was then created based on potential market support, the results of the analysis of the existing supply of rental housing, the availability of land, and the desired scale of the project. These figures may be conservative given the recent announcement by a major area employer, BellSouth, to relocate within the Lindbergh Station area, which may serve to accelerate the absorption of residential property, and particularly owner-occupied units.

Results. Population estimates for the area indicated average annual growth of 1.12 percent, which was significantly below the Atlanta metropoli$\tan$ area growth rate of 3.06 percent per year for the years 1990 to 1997 . Projections for the years 1997 to 2002 indicated an even slower growth rate. In addition, the population of the residential market area is significantly "older" 
than that of the Atlanta metro area. Of the total population, 13 percent was younger than 15 years old in 1997, compared with 22 percent in the metro area. The proportion of the population that was 65 years of age and older was almost 15 percent in the market area, compared with 9 percent metrowide. Median age in the market area had been increasing since 1990, from 34.1 years to 36.7 years in 1997. Comparable figures for the Atlanta metropolitan area were 31.5 years and 33.8 years, respectively.

The potential demand analysis for the entire residential market area estimated a total demand of 8,432 market-rate rental units and 7,125 market-rate, for-sale units during the years 1997 to 2002 . Renter households qualify for these units with annual incomes of $\$ 25,000$ to $\$ 50,000$, and qualified buyers have annual incomes of $\$ 35,000$ or more. Under the 20 -year residential development program proposed for the Lindbergh Station site, 4,500 new rental units and 975 new owner-occupied units would be planned. The required capture rates for this development program at the Lindbergh Station site are 0.03 percent of total demand for rental product and 0.005 percent of demand for forsale product within the residential market area. ${ }^{12}$

Based on these results, the development proposal recommends that an average of 225 rental units be built each year of the 20 -year build-out schedule. The unit mix of the proposed rental housing program should be one-, two-, and threebedroom units. Approximately 40 percent (1,800 units) of new rental housing should be one-bedroom units with a median area of 750 square feet. The primary target market for the one-bedroom units are singles who have the financial capacity to live alone. Two-bedroom rental units should average 900 square feet and comprise 45 percent $(2,025$ units) of total rental housing. Primary target markets for these units include roommates, young couples, empty nesters, and retirees. Applying the same methodology to assess residential demand across product type suggests a smaller demand for larger, three-bedroom units. Specifically, this analysis suggested that the remaining 15 percent (675 units) of the rental housing program should be three-bedroom units averaging 1,200 square feet. These units will be primarily targeted at younger families and roommates. As indicated above, it is critical to provide a variety of housing types at a variety of rental prices. However, this assessment of the demand for various 
types of residential product suggests that a limited amount of demand exists for larger, more expensive units.

The fact that only 18 percent of the proposed residential program for the Lindbergh Station site is targeted at potential owners is based on the observation that attached for-sale units are absorbed more slowly than rentals in this housing market. Absorption of rental units is consistently strong in this market, averaging from 12 to 20 units per month. On the other hand, the sale of attached for-sale units in this market has historically been slow, primarily due to the wide range of housing choices available to potential homeowners. In the competitive product survey conducted for this research, the average absorption of owner-occupied, attached housing was 1.0 unit per month or less.

Therefore, this analysis indicates that an average of 34 attached for-sale units per year should be scheduled for the Lindbergh Station site. Approximately 35 percent of the units should be one bedroom; 60 percent, two bedroom; and 5 percent, three bedroom. Based on competitive products elsewhere within the competitive market area, the suggested average size should be larger in comparison with the rental units-800, 950, and 1,400 square feet, respectively. A key issue for TOD in the area is the provision of owner-occupied housing in the $\$ 130,000$ to $\$ 170,000$ range. The analysis of the residential-owner market found that few units are for sale in this range, and recent projects have had trouble meeting sales goals, resorting to gap financing. No unit in the area is priced below $\$ 150,000$, and the majority are priced much higher.

Estimating Commercial Demand. For the retail market analysis and proposal, a primary retail trade area was defined for the Lindbergh Station site (Figure 6). The primary trade area is the geographic area from which the great majority (approximately $80 \%$ ) of customers originate. The delineation of the retail trade area is based on drive-time estimates, geographic boundaries, and the location of existing shopping centers. The primary trade area for the Lindbergh project is bounded by West Wieuca Road, Nancy Creek Road, and Harts Mill Road on the north; the Georgia Railroad on the south; I-285, Oak Grove Road, and the Lawrenceville Highway on the east; and Northside Drive, Marietta Boulevard, and the Southern Railroad on the west. 


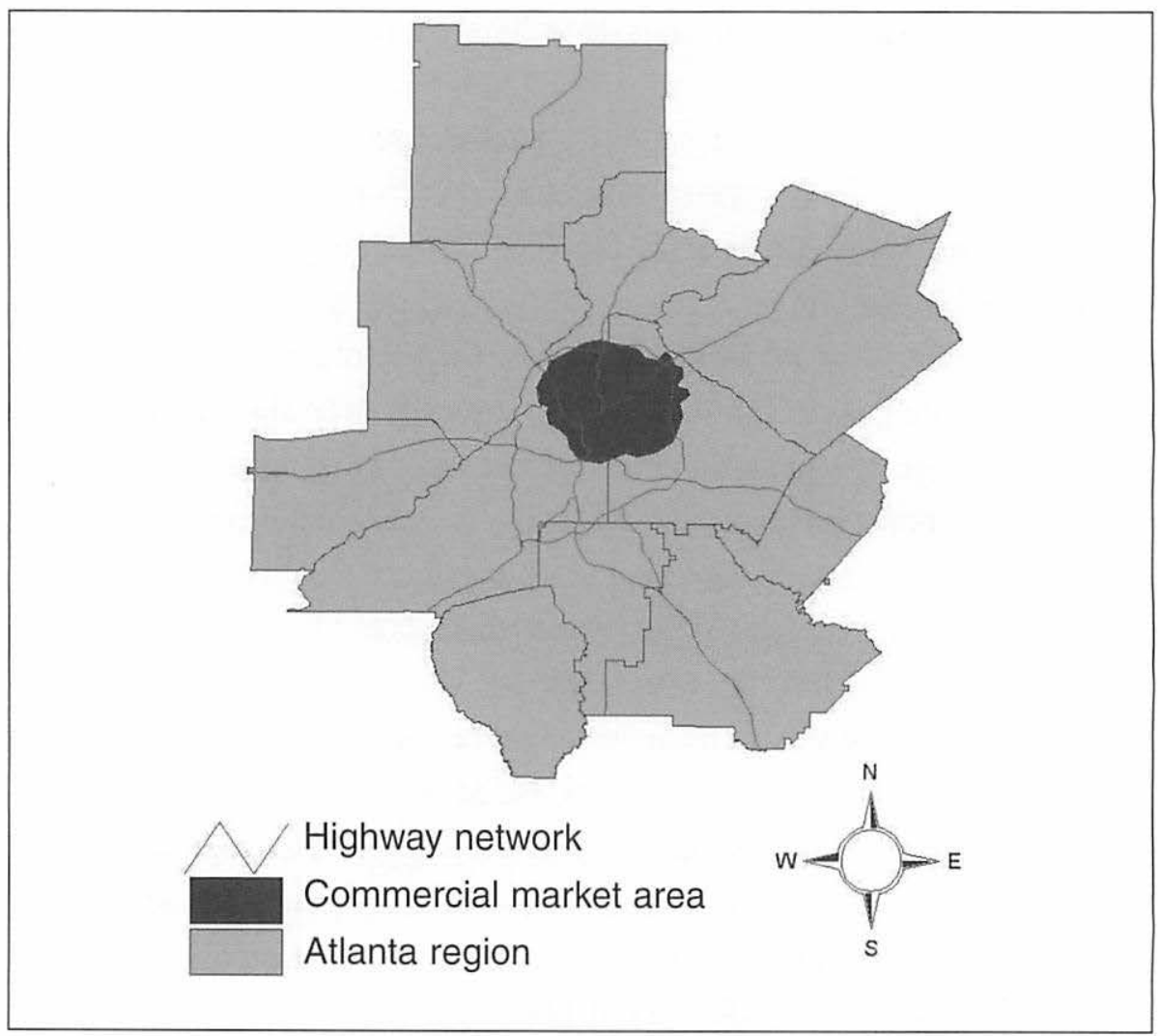

Figure 6. Commercial market area

Although a full demographic and income profile was not completed for the retail trade area, psychographic data from CACI Marketing Systems' ACORN were analyzed to provide a "lifestyle" profile of area households. Since people who share the same demographic characteristics and have similar needs may have widely divergent wants and preferences, these data are considered useful market analysis tools. In this analysis, households within the trade area are grouped into clusters or segments that bear descriptive names meant to convey a type of neighborhood or lifestyle.

To reinforce the ACORN data, CACI estimates of retail "market activity" for specific goods and services were evaluated. While there is no statistical relationship between the market activity data and psychographic data provided by ACORN, inferences may be drawn to identify market opportunities. The 
Purchase Potential Index (PPI) and the Spending Potential Index (SPI) are measures of market activity developed by CACI Marketing Systems. The PPI measures the consumer's tendency to buy certain goods and services, and the SPI denotes actual dollars spent on these goods and services. When the PPI or SPI is equal to 100 for a specific type of merchandise, it indicates that consumers are buying at a rate equal to the national average for that category. A PPI or SPI greater than 100 indicates that consumers are buying or spending above the national average. In other words, the PPI indicates if demand for a product or service in the trade area is higher or lower than average, while the SPI indicates what prices consumers will actually pay. In addition, 10 competitive shopping centers located within the primary retail trade area were surveyed to obtain information on occupancy levels, lease rates, and general character. All the shopping centers surveyed were strip centers.

Results. The population of the commercial trade area was 227,715 , comprising 110,561 households. The median age of the trade area population was 35.9 years, with a median household income of $\$ 41,469$. The trade area population was somewhat older than that of the Atlanta metropolitan area (35.9 years, compared to 33.8 years), as well as less affluent ( $\$ 41,469$ median household income, compared with $\$ 46,765)$. According to the ACORN data described above, the top consumer groups in the retail trade area are high-rise renters $(25.7 \%)$, enterprising young singles (17.4\%), urban professional couples $(13.0 \%)$, active senior singles $(9.3 \%)$, and twentysomethings $(7.9 \%)$.

The top two lifestyle segments, high-rise renters and enterprising young singles, are in the "up-and-coming-singles" group. They have money and they are willing to spend it. They are active, ambitious, and well educated. The third ranking segment, urban professional couples, is in the "upscale households" group. Most are married couples approaching or at middle age. They spend money on vacations, home furnishings and improvements, the theater, concerts, and dining out. The active senior singles segment is comprised of middle-income seniors who are active and well educated. They use coupons and spend money on specialty food items and books. Finally, the twentysomethings are young, active, and urban. Most are single and well educated. 
Overall, the market activity data indicate that trade area residents buy merchandise and services at rates that are higher than the national average. With only a few exceptions, they spend at a level that is also above average. For example, consumers in the trade area buy entertainment at a rate 3 percent above the national average ( $\mathrm{PPI}=103)$ and spend 13 percent above average (SPI=113) on entertainment. Within the entertainment category, concerts and theater had a PPI of 138 and an SPI of 106. While consumer demand for apparel in the trade area is at the national average (PPI $=100)$, consumers spend 7 percent above average (SPI=107) on apparel. Similar retail activity is seen in the household furnishings category, where the PPI=100 and the SPI=106. Consumers eat in restaurants at a rate of 11 percent above the national average (PPI=111) and spend 8 percent above the national average (SPI=108).

A Program for Commercial Development. A recommended commercial development schedule for the Lindbergh Station site was created based on the results of this analysis, the availability of development sites for commercial use, and the desired theme and scale of the Lindbergh redevelopment project. The development program for the Lindbergh Station site envisions a total of 345,000 square feet of retail space by the year 2017. Approximately 18 percent of this space should be allocated to a central market built early in the schedule to serve as an anchor for the remaining retail and service space. Such a market should include shops, eateries, arts and crafts, fresh produce, and gourmet food items. These storefronts are intended to have the appeal of New York City vendors with decorative awnings and lots of space available for product display. The market itself should encompass 70,000 square feet and serve as an anchor for almost four times as much additional retail, focusing particularly on restaurants and theaters. These economic development initiatives will require a strong partnership between the neighborhood, developer, and transit authority, as well as a public relations and marketing campaign to improve the perception of the public and attract transit users to the development.

The recent announcement by BellSouth to participate in the redevelopment will serve to anchor the station area as an emerging employment center. BellSouth's plan to locate $1,000,000$ square feet of office space at the 
Lindbergh Station will be in the form of two 17-story office towers. If realized, this may serve to increase the demand for housing and retail services above the more conservative estimates reflected in the analysis.

\section{Summary and Recommendations}

The analysis of the Lindbergh Station area TOD bridges physical planning and economic development considerations. This approach is applicable elsewhere and represents an incremental improvement over assessments that do not integrate these dimensions. If TODs continue to be considered both as pleasant alternatives to standard developments and as partial solutions to the urban problems of congestion and poor air quality, the approach described here, which effectively incorporates market demand, should be further cultivated and seriously considered by developers and municipalities. It begins to provide direction for communities that do more than simply serve as physical models of this type of development. Based on this level of analysis, a transit authority, municipality, and local neighborhoods have the ability to understand the types of residents, businesses, and shoppers that can be attracted to the area. This enables the translation of models into a reality that can begin to give shape to a physical plan for redevelopment.

The analyses and recommendations produced by the approach described here provide an essential foundation for effective analysis of TOD plans, but remain ineffective in the absence of some key ingredients of the implementation phase of development. The Lindbergh Station area project provides a good illustration of the importance of these components to successful completion of TODs that remain true to their underlying purpose and concept. Figure 4 provides a schematic design developed for the study area that integrates the physical project recommendations from each of the four focus areas.

It is recommended that the first phase of redevelopment take place on land owned by MARTA that is currently occupied by the parking lot for the transit station. This parking lot creates an unattractive barrier for pedestrian movement between Piedmont Road and the station itself. Furthermore, this parking facility is a large underdeveloped space in the center of an area that offers high potential for value capture. Based on the research, the area should be 
redesigned as a mixed-use area to include some housing above first-floor retail or restaurant uses. Owner-occupied housing should be located above the transit station itself where transit access is greatest. The design for the area should build on a grid system of streets, including a wide pedestrian walkway linking the station with a plaza or other open space at the intersection of Lindbergh and Piedmont Roads (see Figure 2). The streets to be constructed in this area should be narrow but should provide vehicular access. The network of streets with a grid pattern should be continued across Piedmont Road in the area currently occupied by a large commercial parking lot. Finally, a series of pocket parks and plazas should be constructed to physically and visually link the various parts of the district and provide nodes to pedestrian routes and crossing points.

While Figure 4 outlines a circulation and layout concept for the proposed redevelopment, it does not attempt to allocate the commercial and residential growth over time in the study area. In addition, current resistance on the part of the neighborhood groups, even in light of the significant effort placed on outreach, suggests the significant need for resources targeted at cultivating a workable plan that the local community can embrace. In the case of the Lindbergh Station area redevelopment, work is required to overcome the existing pedestrian barriers that are created by Lindbergh and Piedmont Roads. To resolve issues that extend beyond the confines of the MARTA property under immediate attention for redevelopment are the issues associated with the larger area that defines the "station area."

This is particularly important for the transit-dependent populations located across Piedmont Road to the east. At play are conflicting institutional concerns governing transportation funding priorities and agency mandates.

These large-scale issues, which extend beyond the immediate area of redevelopment, are critical for the project to be able to achieve the goals of a livable community and to provide a model for the region of transit-supportive development that can assist in meeting air quality objectives. ${ }^{13}$ While neighborhood groups are highly aware and somewhat supportive of the project, they have recently been voicing major opposition regarding traffic impacts and lack of sidewalk connections associated with the project along these corridors.

Partnerships must be built between and among MARTA, the developer, the 
neighborhood, the City of Atlanta, and the federal government. Each of these parties is currently involved in the project in some way, but coordination and cooperation is insufficient to assign responsibility that otherwise falls between parties. The FTA, for example, has contributed funding for the project under the Livable Communities Initiative and expects development of the area to follow the guidelines set forth by that program that are reflected in the goals noted earlier in this article. If those principles are not followed, the larger community, defined here to include the neighborhoods that surround the redevelopment area, stand to lose the opportunity of effectively benefiting from the redevelopment.

The full range of potential funding sources must be understood and utilized. Possible avenues for funding currently include the Transportation Enhancement Activity portion of TEA-21 funding; Congestion Mitigation and Air Quality funds; and 33C monies. ${ }^{14}$ Again, it is absolutely essential for partnerships to form early in the process and focus cooperatively on the task at hand: developing the MARTA acreage in a transit-oriented fashion that facilitates and encourages additional interconnected redevelopment of surrounding areas. This task cannot be effectively approached without adequate funding, and the range of sources available can be complex and confusing.

The Lindbergh project is in danger of falling into the common trap of tunnel vision. Many redevelopment efforts of this type tend to focus exclusively on a single parcel, ignoring the larger geographic context. Instead, planners and developers must include the corridor and community as a whole if their plans are to succeed. For example, the immediate area around the Lindbergh Station is separated from the surrounding community by railroad tracks on one side and Piedmont Road on the other. In cases such as this one, planning only for the site in question will result in an island of development that has no hope of serving either significant numbers of pedestrians or the residents of the neighboring community. Connectivity with the overall community is an essential element of the TOD, and a narrower, parcel-level planning destroys this important component. This goal can raise the question of responsibility when several owners and stakeholders are involved, and often results in disagreements and finger-pointing. Consensus-building efforts must be sufficiently 
effective to enable the creation and implementation of a cohesive areawide plan.

\section{Acknowledgments}

The authors would like to thank Dan Cohen at the city of Atlanta Bureau of Planning and the Turner Foundation for providing funding for the study on which this article is based. A special thanks is given to the students that were in the city planning studio course at Georgia Tech, which conducted some of the early analysis of the Lindbergh Station area. These students were Lakey Broderius, Alicia Corral, Mary Darby, Johnny Dunning, Philip Harris, Dorita Herd, Kiesha Johnson, Brian Leary, Beth Prins, Bratten Thomason, and Douglas Wolf.

\section{Endnotes}

1. The Atlanta Regional Commission (the area's federally designated metropolitan planning organization) has recently conducted a "Land Use Sensitivity Analysis" to test the comparative effects on travel choice associated with focusing growth into MARTA station areas (Atlanta Regional Commission, Land Use Task Force Results 1999). The results of this analysis, with a 2020 planning horizon, was a 31.6 percent increase in home-based work and a 17.9 percent increase in homebased, nonwork trips via transit. However, the same analysis did not reveal similar reductions in SOV travel.

2. One of the more creative and exhaustive fund-raising efforts for transit station area redevelopment can be found in association with the Fruitvale Bay Area Rapid Transit Station, for which a wide variety of private and public monies have been pooled to implement an areawide redevelopment plan.

3. The current site of the Lindbergh Station area redevelopment was formerly an international market.

4. This practice requires unique circumstances where an alternative right-of-way is available for separating directional travel into one-way pairs. Such a practice would be used to address negative impacts of pass-through travel often associated with state-owned routes.

5. MARTA received a grant from the FTA through the Livable Communities Initiative Program for the redevelopment of the Lindbergh Station area.

6. A great deal of these units are part of the post-Lindbergh development, which is adjacent to the Lindbergh Station. 
7. Home ownership was also found to vary systematically with income and race.

8. Housing values in this central portion of the Atlanta region have risen dramatically since the time these data were collected.

9. The Lindbergh Station is the location along the north-south MARTA alignment where two lines from the north (Dunwoody [along I-400 north] to Doraville [northeast]) merge into one heading south.

10. It is possible that these streets need not be one way but could rather serve to distribute the north-south flow through the station area, enabling Piedmont Road itself to become less of a barrier for pedestrian movement. One-way streets have been found to increase travel speed and are often difficult from an economic development perspective.

11. The City of Atlanta has requested enhancement funds under Transportation Equity Act for the 21st Century (TEA-21) for several of these needed pedestrian improvements.

12. These capture rates are conservative. They are based on historical trends within the residential market area defined above.

13. Governor Roy Barnes recently signed into law an act that establishes the Georgia Regional Transportation Authority (GRTA). The authority will have significant oversight concerning transportation funding and its relationship with major local land-use actions. GRTA will have the capacity to support projects such as the Lindbergh Station area redevelopment that have significant potential to improve air quality and offset automobile dependence. In particular, GRTA may have the financial capacity to leverage federal funding required to establish pedestrian linkages required for a successful redevelopment effort.

14. TEA-21 makes several new provisions for the funding of transit-supportive development including new funds for creating environmentally sustainable communities that include the Transportation and Community System Preservation Pilot Program.

\section{References}

Antoniou, James. January 1971. Planning for pedestrians. Traffic Quarterly.

Berechman, Joseph. 1995. Transport infrastructure investment and land use. In Transport and Urban Development. David Banister, ed. London: E \& FN Spon. Bernick, Michael, and Robert Cervero. 1997. Transit villages in the 21st century. McGraw Hill. 
Burchell, Robert, and D. Listoken. 1974. The costs of sprawl: Environmental and economic costs of alternative residential development patterns at the urban fringe. Washington, DC: U.S. Government Printing Office, Council on Environmental Quality.

Calthorpe, Peter. 1993. The next american metropolis: Ecology, community, and the American dream. Princeton: Princeton Architectural Press.

Cervero, R, and R. Gorham. 1995. Commuting in transit versus automobile neighborhoods. Journal of the American Planning Association 61 (2):210-225.

Cervero, Robert, and Kara Kockelman. 1997. Travel demand and the 3Ds: Density, diversity, and design. Transportation Research Part D 2 (3):199-219.

City of Portland. 1980. Downtown design standards.

Ewing, R., P. Haliyur, and G. W. Page. 1994. Getting around a traditional city, a suburban PUD, and everything in-between. Transportation Research Record 1466.

Florida Department of Transportation. 1995. Walkable communities. State Safety Office, Pedestrian/Bicycle Program.

Frank, Lawrence. 1998. Reducing vehicle emissions through growth management and travel reduction strategies. Journal of Urban Planning and Development 124 (1):11-32.

Frank, Lawrence D. January 1999 (forthcoming). Land use and transportation interation: Health and quality of life implications. Journal of Planning Education and Research.

Frank, Lawrence, and Gary Pivo. 1994. Relationships between land use and travel behavior in the Puget Sound region, Final Summary Report, Washington State Transportation Center.

Metro. 1997. Metro regional street design handbook. Portland, Oregon.

Moudon, A., P. Hess, and M. Snyder. 1996. Effects of site design on pedestrian travel in mixed-use, medium-density environments. Paper submitted to 75th Annual Meeting of the Transportation Research Board, Washington, DC.

Newman, Peter, and Jeffrey R. Kenworthy. 1996. The land-use transport connection. Land Use Policy 13 (1): 1-22.

Parsons, Brinckerhoff, Quade, and Douglas Inc., with Cambridge Systematics Inc., and Calthorpe Associates. 1993. LUTRAQ-Making the land use transportation air quality connection: The pedestrian environment. Portland, OR: 1000 Friends of Oregon.

Pushkarev, B. S., J. M. Zupan, and R. S. Cumella. 1982. Urban rail in America: An exploration of criteria for fixed-guideway bus. Report Number UMTA-NY-060061-80-1, U.S. Department of Transportation. Urban Mass Transportation Administration. 
Schimek, Paul. 1996. Household motor vehicle ownership and use: How much does residential density matter? Transportation Research Record 1552.

Untermann, Richard K. 1984. Accommodating the pedestrian: Adapting towns and neighborhoods for walking and bicycling. New York: Van Nostrand Reinhold Company, Inc.

U.S. Department of Transportation. December 1989. A guide to land use and public transportation.

\section{About the Authors}

LaWrence D. Frank is an assistant professor in the City Planning Program at the Georgia Institute of Technology. He is a Registered Landscape Architect, and holds a master's degree in civil engineering transportation planning and a Ph.D. in urban design and planning from the University of Washington. Dr. Frank does research and writes on the relationships between land development, travel choice, vehicle emissions, and household physical activity levels. He recently authored the Project XL proposal to the Environmental Protection Agency for the redevelopment of the 138-acre Atlantic Steel brownfield in Atlanta into a 12 million square foot transit-oriented community.

Mollie STEPHENSON SMith is a senior transportation planner at CRA Associated, Inc., in Atlanta, and holds a master's degree from the City Planning Program at Georgia Institute of Technology. Ms. Smith has worked on a variety of projects that involve multimodal transportation concerns.

ELEANOR Q. MATTHEws is the principal of MARKETEK, Inc., which specializes in the assessment of consumer demand for various real estate products. MARKETEK, is involved in a variety of projects throughout the southeastern and central portions of the nation. Ms. Matthews is a graduate of the City Planning Program at the Georgia Institute of Technology. 